\title{
Female Feticide: A Social Evil in India (Challenges before Us)
}

\author{
Ms. Rajani Srivastava \\ Research Scholar, Banasthali Vidyapith
}

\begin{abstract}
In a modern time, Female feticide--the selective abortion of female fetuses, females not only face discrimination in this culture, they are even denied the right to be born female feticide determined by many factors, but mostly by the vision of having to pay a dowry to the upcoming bridegroom of a daughter. While birth of the baby boy offer refuge of their families in old time and can execute the rites for the souls of late parents and ancestors, daughters are treated as a social and economic encumber. In India feticide is a moderately new practice, rising concurrently with the advent of technological advancements in prenatal sex determination on a large scale in the 1990s. Detection technologies have been distorted, allowing the selective abortions of female offspring to proliferate. Legally, however, female feticide is a penal offence although female infanticide has long been committed in India, According to the Census 2001 report the declining sex ratio which has been dropped to alarming levels, female feticide become common in the middle and higher socio-economic households, especially in north zone because of the low status of women such as dowry, looking up for son, as concern with family name are the main evil practice performing sex selection abortions in India. There is an urge to reinforce the law to stop these kinds of illegal practices, it impact overall societies especially on women. The paper will discuss the socio-legal challenges female feticide presents, as well as the consequence of having too few women in Indian society.
\end{abstract}

Key Words: Sex Ratio, Feticide, Sex Selection Abortion, Technology

\section{Introduction}

"Mahatma Ghandhi" said, a woman is the companion of man, gifted with the equal mental capacities she has the right to participate in the minutest details of the activities of man, and she has the same right of freedom and liberty as he. She is entitled to a supreme place in her own sphere of activity as man is in his. Man and woman are equal in status, but are not identical. Female feticide is one of the extreme manifestations of violence against women a social problem that is now spreading unchecked across the country. Female foetuses are selectively being aborted after pre-natal sex determination, thus denying a girl's 'RIGHT TO LIFE'. They are a peerless pair being complementary to one another; each helps the other, not that without the one, the existence of the other cannot be conceived; and, therefore, it follows as a necessary result from these facts that anything that will impair the status of either of them will involve the equal ruin of both. According to (Manu), a woman has to be reborn as a man to attain moksha (redemption). A man cannot attain moksha unless he has a son to light his funeral pyre. Also, it says a woman who gives birth to only daughters may be left in the eleventh year of marriage. The neglect of and discriminatory behavior against girls leading to excess female mortality has been widely documented by several studies, but the recent increase in the juvenile sex ratio discussed above has very likely resulted from rapid spread of ultrasound and amniocentesis tests for sex determination in many parts of the country, following by sex-selective abortions. Because of simplicity of the tests and their easy availability on the other hand there is a strong son preference on female-specific abortions appear to have become popular and widely used people generally thought that the cost of the test and related abortion is much lower than the cost of providing dowry and other life-long presentations to a daughter after marriage. According to (Chaudhury 2003), the alarm bells ringing in the corridors of power about the missing girls do not find an echo in the dusty by-lanes of the villages in India. It is important to understand the emergence of this phenomenon in a wider perspective. India pioneered in legalizing induced abortion under the medical termination of pregnancy (MTP) Act, 1971 that specifies the reasons for which an abortion can legally perform the abortions and kind of facilities in which they can be carried out. The stipulated conditions are such that abortion performed by trained doctors who are not registered in facilities not specifically approved for abortion services are termed illegal.

According to (Chhabra and Nuna 1993), in India illegal abortions may be 8 to 11 times as. While the intention is to provide women with safe, legal, timely abortion services, given the stringent nature of the Medical Termination of Pregnancy act, many safe abortions may be classified as not legal. Abortion can be legally availed if a pregnancy carries the risk of grave physical injury to a women, or endangers her mental health or when pregnancy result from a contraceptive failure or from rape or is likely to result in the birth of a child with physical or mental abnormalities. Methods to detect deformities in the foetus such as amniocentesis and sonography that use ultrasound technology providing valuable and early information on a range of physical 
problems have become available in the country. However, the technologies that help detect physical or mental abnormalities in the unborn child can also identify the sex of the foetus at no extra cost or effort. There was increasing indirect evidence from some parts of India that termination of pregnancies was resorted not for the reasons stated under the MTP act but because there is a strong son preference leading to female- selective abortions. The gender bias was flagrantly aided by a combination of medical technology that helped detect the sex of the foetus on the one hand and the liberal abortion law that helped couples to abort female foetus on the other.

In view of this, the Indian government, responding to the petition made by non- governmental organizations and women's groups, passes an act prohibiting the practice of pre-natal diagnosis of sex of the foetus (Pre- Natal Diagnostic Techniques [PNDT] act of 1994). Under the Act, individual practitioners, clinics or centers cannot conduct tests to determine the sex of the foetus or inform the couples about it before the passing of the PNDT Act in 1994, it was evident that clinics conducting sex determination tests had mushroomed in many towns in the states in the north- western belt. The open advertisements have now disappeared but the lucrative practice seems to flourish unabated by simply going underground as evident from the continued decline in the sex ratio of children 0-6 years of age. Although the release of the 2001 Census, results has sparked serious concern about the widespread use of ultrasound and amniocentesis tests to detect the sex of the foetus, following by sex-selective abortions, our understanding of many issues around this practice, at the level of the household or form the perspective of women who undergo such abortions, is extremely limited. It is also limited about what actually compels couples or their families to resort to such a practice, who the real decision makers in the family are, what impact does aborting female foetus have on the physical or mental health of the women who typically undergoes abortion in the second trimester of her pregnancy.

When women were asked about the decision making process if the foetus was found to be that of a female child, the overwhelming response was that after one or two daughters, if the women was found to be pregnant with another girl, the pressure on her to abort was enormous from her extended conjugal family. Women indicated that the decision to abort a female foetus was almost entirely that of their husbands and/or mothers- in-law. By themselves, women could not take the decision to go in for abortion. Women, who had virtually no decision-making power, apparently accepted whatever was desired by her conjugal family, including husbands. They simply accepted and went along with the decision made for them by others. We observed that women belonging to the higher social group sometime they themselves desire to abort a female foetus because they already have had one or two daughters. This feeling was strong among women belonging to highly educated social groups, who valued sons much more than daughters. Although they themselves, without much hesitation, would opt for abortion, they still would have to get the permission of the elders of the family to exercise their wish. According to (Manmohan Sharma 1999), activists in Punjab pointed out: "women are conditioned by social norms and they do not have independent views, they tend to ditto what the husbands say or think and this is considered as proper behavior for ideal wives'.

According to (Wertz and Fletcher 1993), Liberty and value for human life are integral principles within the context of human rights. In the domain of female feticide these principles conflict. While pro-life supporters condemn as immoral the practice of female feticide, the parents assert their right to have a family of a particular sex composition. Legal support to discriminatory elimination of life is stated in the PNDT Act. Yet the principal of liberty, voiced as a parental choice to desire a small and sex-defined constituent family, falls in the gambit of a criminal choice. To attribute primacy to right to birth rather than to all-encompassing right to life is a reductionist approach. It is evident that cultural predispositions could not deny the right to birth, but could distort the natural life cycle (e.g. female infanticide). As is evident, legislation banning the use of sex determination tests has thus far not succeeded in deterring couples from seeking these tests or preventing the medical practitioners from performing them. Fundamental Rights, among others, ensure equality before the law and equal protection of law; prohibits discrimination against any citizen on grounds of religion, race, caste, sex or place of birth, and guarantee equality of opportunity to all citizens in matters relating to employment. Articles 14, 15, 15(3), 16, 39(a), 39(b), 39(c) and 42 of the Constitution are of specific importance in this regard. To uphold the Constitutional mandate, the State has enacted various legislative measures intended to ensure equal rights, to counter social discrimination and various forms of violence and atrocities and to provide support services especially to working women. But above all supportive measures women's treated as a second citizen in our society she do not even right to take decision for her own after the completion of 66 years of independence, no choice for her carrier, marriage she always saw the face of her man (father/husband/son) for taking a small decision even if now.

The maiden episode Satyamev Jayate is regarded as an eye-opener as it highlighted how unethical medical practitioners are hand in glove with families wanting to kill the female unborn baby and how highly educated women's are also involved in it. "The show is extremely hard hitting. It's strange that the most well educated women's carry out the worst of crimes like female feticide. First, people pay to get the girl child 
aborted, and then they pay to buy girls in order to fulfill their sexual needs and to give birth to their sons. Where is the common sense in all this," asked Ravinder Kaur, a professor.

\section{Networking Of Government Doctors, Private Doctors, Anms And Dais}

During our study we found sense a silent conspiracy between the government doctors, medical and paramedical staff and private doctors with regard to the illegal practice of sex determination tests leading to female feticide. The dais and ANMs often as go betweens and collect their honorarium. We also analysis that medical representative are a party to the game of making quick money. A tragic aspect of this is that very often doctors show utter disregard for medical ethics. The doctors know very well that through ultra sonography it is not possible to determine the sex of a foetus within 12 weeks of conception and yet they conduct these tests and indicate the results (invariably 'it is a girl'). Generally, this test is conducted only during the second and subsequent conceptions. But in few states like Punjab, Haryana, Chandigarh these kinds of test conducted even for the first conception. There were also cases of murder within the family when the young daughter-in-law refused to go for abortion after the very first conception. In rural areas where poorer people who were unable to afford MTPs went to quacks, often with fatal result. One such quack was a lady know as the 'Dai', she used to sweep and mop in a doctor's clinic she is very popular among the people in the PHC area. Even in till date there is a huge violation of the act has been carried out due to the lust of the money making, even after the Supreme Court order we need to find out the long lasting solution for the cure of the problem and need to take collaborative step.

Sex ratio refers to ratio of females to males in a given region. Practices like female foeticide and female infanticide (killing a baby girl after she is born) have had an adverse effect on the sex ratio of a nation and gives rise to further social evils. As per the Indian Census 2011 report, the sex ratio of India (females per 1000 males) is as follows:

Average India sex ratio - 933, Rural sex ratio - 946, Urban sex ratio - 900, State with highest female sex ratio - Kerala - 1058, State with lowest female sex ratio - Haryana - 861 .

Thus, we arrive to a conclusion that female foeticide is a devil in itself that lives amongst us and torments the lives of people all around it. So let's stand united and fight against this growing parasite.

\section{Objectives Of The Study:}

- To generate awareness/education among women's regarding 'Right to Life'.

- To analysis the status of women in decision making process.

\section{Methodology}

A sample of nearly 50 respondents among the married women's belongs to higher educational population was selected from Banasthali University. The total universe size is 125 stipulated in the research. The sample for this study will be selected through random sampling method. The study is delimited to married women who are in the age group of 25 - 35 years in the Banasthali University. In whole of the study primary source of data collection has been through structured questionnaire was developed regarding evidence based causes of female foeticide and development of strategies to change the mind set as well awareness regarding human rights for the study, in questionnaire a series of questions collected appropriate data for analysis purpose so that answers to the searching questions raised as well as specific objectives of the research study accomplished. The data will be analyzed on percentile basis.

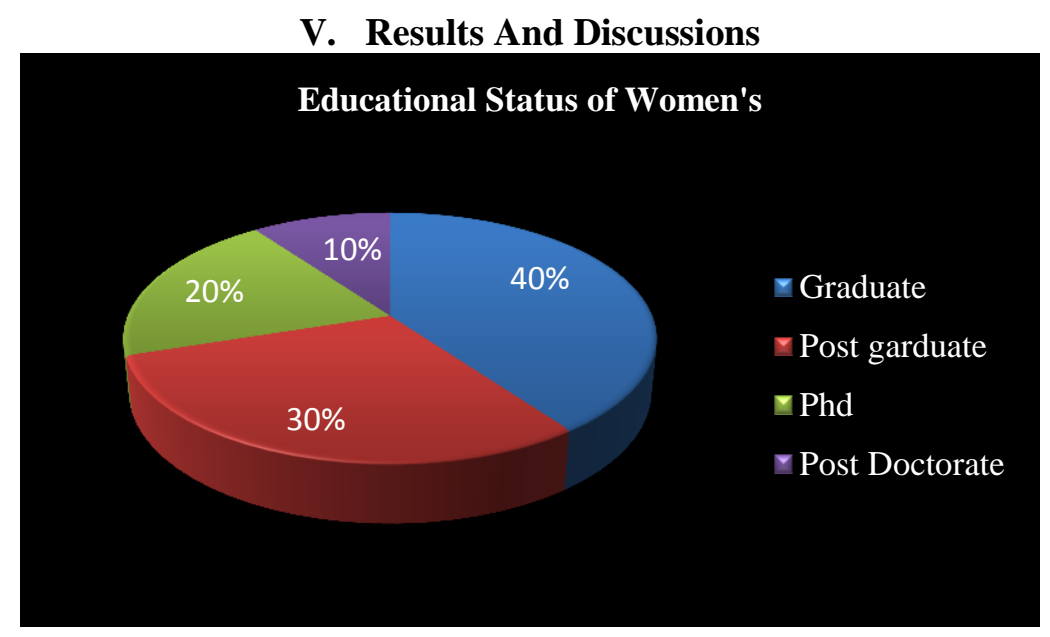


Data in the above figure revealed that, $40 \%$ of engineering graduate faculties preferred first male child. $30 \%$ women's completed her post graduation in different subjects like management, social work, and commerce we mainly compare their views found that they do not cleary show their preference but in a hidden way they want male child due to future security.

Whereas and 20\% women's completed their Phd in different streams found that they prefer male child but not rigid with their views if they have female child they happily welcomed her and ready to carry their responsibilities and never even think about the violate of human right "Right to Life".

$10 \%$ of Post Doctorate do not show their specific choice according to data they believe in no matters weather it's a male child or female child the only thing is that the child should be healthy they know the pros and corns of foeticide.

Means there is need to promote education and need people to get aware about this serious issues women's having science background they were less aware about the laws related to female foeticide that may be they were not aware that this issue is a dam serious if we are not concentrating on this timely so it is very hard to recover our casualties in coming future.

\section{Conclusion}

The preference for a male child in large sections of our society even in highly educated groups to the root cause of an imbalanced sex ratio "Foeticide was invented, touted and sold by the medical profession, and it operates with the complete consent of all factors of our society.

Hence, above data shows that education plays an important role in women's life higher education extend the dimension of thought process of human being and it is also true that an educated woman can educate her upcoming seven generations. But we cannot deny this reality to that after getting a good education there are many constraints were waiting for women like family pressure, male dominancy, less power on resources etc which has bound the steps of women to take her own decisions and finally she have to do all they (including husband \& in-laws) want. "We do not have the time to play around with these chocolates and ice-cream solutions. We have to do something more serious. All agencies must immediately join hands and launch a stricter crackdown so that no medical professional in this murderous practice can escape.

The study made it clear that a woman whether educated or highly educated rich or poor was not conscious of her own identify. It may be concluded that the banning of sex-determination test, though an essential and urgently required step, is not the final solution to the problem. In the long run, social prejudices against women have to be overcome by improving her status in society. So, Jaago India Jaago!!

\section{Suggestions}

Apart from constitutional and legal provision we need to do apply few more steps for banning female foeticide in India like, through wide companying, road shows, nukkad natak, spreading education among educated people because they do not have time in their busy clock so they need to skip time and keep concern towards this dam serious issue otherwise no doubt that the alarming bell is ringing over the head of our society that the society without the female for ex. Haryana, Chandigarh where the boys parent's were bagging for girl for the purpose of marriage from the other states without dowry. The long-term strategies should include education and empowerment of women. Empowerment among women's and education to improve their lot will heighten their status in the society. As the women sangthans and the federation gain in importance and play a greater role in the development of the area, it is hopes that their presence and the politico-economic strength they enable will help curb the practice. Also Media-both print and electronic-plays a very significant role in removing gender bias and developing a positive image of the girl child in the society, It is not easy to change overnight the attitude of even women towards females infanticide. Even if the women are prepared to understand and accept the need to change, the social situation and the family environment prevent them from doing so. Therefore, young married couples and pregnant women were given counseling so that they could cope with the situation, because they are surrounded by in laws and neighbors who are pro-female infanticide.

\section{References:}

[1]. Prof. Tulsi Patel, sex- selective abortion in india (gender, society and new reproductive technologies, Saga Publication House IndiaNew Delhi, Department of sociology, 2007).

[2]. Kusum Jain, and Anju Sachdeva, Attitude of Urban Societies towards Female foeticide, Advanced International Research Journal of Teacher Education, Vol. 1, No. 1, 2013, 83-86.

[3]. Sneh Lata Tandon and Renu Sharma, female foeticide and infanticide in india: an analysis of crimes against girl children in university of delhi, 2008.

[4]. Adhikary.Mita, article on, female foeticide- the devil among us, 2012.

[5]. Chetan Sharma, and divya Jain, government of india on e-governance technology and its impact on female feticide in india, 2005.

[6]. National Legal Research Desk, Article on Constitutional and legal provisions for women in India, 2005. 